\title{
Erratum: Genomic analysis of ERVWE2 locus in patients with Multiple sclerosis: absence of genetic association but potential role of Human Endogenous retrovirus type W elements in molecular mimicry with myelin antigen
}

\section{Camila Malta Romano*}

Departamento de Moléstias Infecciosas e Parasitárias - (LIMHC), Instituto de Medicina Tropical de São Paulo e Faculdade de Medicina, Universidade de São Paulo, São Paulo, Brazil

${ }^{*}$ Correspondence: cmromano@usp.br

Edited by:

Hirofumi Akari, Kyoto University, Japan

Keywords: endogenous retroviruses, multiple sclerosis, MOG, immunopathogeny, genetic association, ERVWE2

\section{A commentary on}

Genomic analysis of ERVWE2 locus in patients with multiple sclerosis: absence of genetic association but potential role of human endogenous retrovirus type $\mathrm{W}$ elements in molecular mimicry with myelin antigen

by do Olival, G. S., Faria, T. S., Nali, L. H. S., de Oliveira, A. C. P., Casseb, J., Vidal, J. E., Cavenaghi, V. B., Tilbery, C. P., Moraes, L., Fink, M. C. S., Sumita, L. M., Perron, H., and Romano, C.
M. (2013). Front. Microbiol. 4:172. doi: 10.3389/fmicb.2013.00172

The correct sequences of the primers described in this work are HW_MSchX F-TGGGTGAAGTAAGTCCAACAG and HW_MSchX_R-TGAAGAACGTATCCAG CCTACA. The amplified fragment corresponds to nucleotides 21227-22122 of the human chromosome Xq22.3 (GenBank ID AL390039.10).

Received: 29 October 2013; accepted: 30 October 2013, published online: 18 November 2013.
Citation: Romano CM (2013) Erratum: Genomic analysis of ERVWE2 locus in patients with Multiple sclerosis: absence of genetic association but potential role of Human Endogenous retrovirus type $W$ elements in molecular mimicry with myelin antigen. Front. Microbiol. 4:345. doi: 10.3389/fmicb.2013.00345

This article was submitted to Virology, a section of the journal Frontiers in Microbiology.

Copyright $(2013$ Romano. This is an open-access article distributed under the terms of the Creative Commons Attribution License (CC BY). The use, distribution or reproduction in other forums is permitted, provided the original author(s) or licensor are credited and that the original publication in this journal is cited, in accordance with accepted academic practice. No use, distribution or reproduction is permitted which does not comply with these terms. 